\title{
The Impact of International Crude Oil Prices on Energy Stock Prices: Evidence From China
}

\author{
Mengting Jiang', Dongmin Kong ${ }^{1}$ \\ 1 School of Economics, Huazhong University of Science and Technology, China \\ Keywords: international oil price, energy stock market, dcc-garch, china \\ https://doi.org/10.46557/001c.28133
}

\section{Energy RESEARCH LETTERS}

Vol. 2, Issue 4, 2021

\begin{abstract}
Based on a vector autoregressive model and a dynamic conditional correlation generalized autoregressive conditional heteroskedasticity model, this study explores the relation between the international crude oil market and the Chinese energy stock market. The findings suggest a positive one-way spillover effect of international crude oil returns on China's energy stock returns. Furthermore, this correlation between the two markets is time varying.
\end{abstract}

\section{Introduction}

Energy is the material basis and guarantee for human survival and economic development. Therefore, fluctuations in the energy market will have a profound impact on the global economy (Li \& Wei, 2018). In particular, with the accelerating urbanization and industrialization in China, oil, as a major energy source, plays an important role in the Chinese national economy. In this regard, international oil price fluctuations will have an influence on China's energy industry and even the macroeconomic environment.

As a barometer of the national economy, the stock market can reflect the dynamic effects of international oil prices on the real economy to some degree. With the increasing relevance between oil prices and financial markets, a number of studies have been recently carried out on the impact of oil price shocks on stock markets. In terms of research subjects, studies have been conducted on both global stock markets (Escobari \& Sharma, 2020; Maghyereh \& Abdoh, 2021) and specific countries and regions (Alamgir \& Amin, 2021; Diaz et al., 2016), and there are also relevant studies from the perspective of oil-importing and exporting countries (Youssef \& Mokni, 2019). Regarding research methods, a series of studies have been conducted using vector autoregression (VAR) models (Cunado \& Perez de Gracia, 2014), quantile regression methods (Joo \& Park, 2021; Mokni, 2020), nonlinear autoregressive distributed lag models (Alamgir \& Amin, 2021), and generalized autoregressive conditional heteroskedasticity (GARCH) models (Diaz et al., 2016).

Most studies are now focusing on the impact of international oil price fluctuations on the overall stock market, with less research on the energy stock market. Several studies examine the impact of oil prices on the returns of companies in different industries and find that the oil price-stock return relation is characterized by asymmetric effects. Based on that, we specially pay attention to the energy market (Narayan \& Sharma, 2011; Phan et al., 2015). A combination of VAR and dynamic conditional correlation (DCC) GARCH models are used in this paper to examine the impact of international crude oil prices on Chinese energy stock prices. The results show a one-way mean spillover effect and time-varying conditional correlation between international crude oil returns and Chinese energy returns. The limitation of this paper is that this claim is not further tested using a different methodology. We leave this matter to future studies.

Our study contributes to the literature in two ways. First, we supplement the literature on the impact of international oil prices on financial markets from the perspective of the Chinese energy market and the VAR-DCC-GARCH approach. Second, we provide theoretical and empirical evidence for Chinese energy enterprises to successfully cope with external shocks and allow investors to more easily and rationally construct portfolios for risk diversification (Awartani \& Maghyereh, 2013). The remainder of this article is organized as follows. Section II presents the data and methods. Section III discusses the results. The concluding remarks are provided in the final section, Section IV.

\section{Data and Methodology}

\section{A. Data}

This study uses the price of West Texas Intermediate oil (WTI) as a benchmark for international oil prices, since it is commonly used as a reference price to reflect the current international oil market. We obtain WTI price data from the US Energy Information Administration. In addition, we select the CSI Energy Index to describe the volatility of the Chinese energy market, since it is reflective of the overall performance of a company's stocks in the sector. We use the bilateral exchange rates issued by the Federal Reserve System for exchange rate conversion.

Our final sample covers a time series of 806 observations from January 1, 2018 to June 31, 2021, as shown in Panel A of Table 1 . We define daily returns as the logarithmic difference between two consecutive prices, as follows:

$$
R_{t}=\ln \frac{P_{t}}{P_{t-1}}=\ln P_{t}-\ln P_{t-1}
$$


Table 1. Descriptive statistics and the results of VAR model

Panel A: Descriptive statistics of the returns for energy and oil.

\begin{tabular}{|c|c|c|c|c|c|c|c|c|}
\hline Variable & Mean & Sd & & Min & Max & Skewness & Kurtosis & $\mathrm{JB}$ \\
\hline Oil & 0.000 & 0.050 & & -.720 & 0.426 & -2.876 & 72.096 & $1.60 \mathrm{E}+05^{* * *}$ \\
\hline Energy & -0.000 & 0.016 & & -.093 & 0.097 & -0.154 & 7.210 & $598.300^{* * *}$ \\
\hline \multicolumn{9}{|c|}{ Panel B: The results of VAR model. } \\
\hline \multicolumn{9}{|c|}{ Part I } \\
\hline Lag & LL & LR & $\mathrm{df}$ & $\mathrm{p}$ & FPE & AIC & HQIC & SBIC \\
\hline 0 & 3471.250 & & & & $6.00 \mathrm{E}-07$ & -8.652 & -8.647 & -8.640 \\
\hline 1 & 3493.160 & 43.820 & 4 & 0.000 & $5.70 \mathrm{E}-07$ & -8.696 & $-8.683^{*}$ & $-8.661^{*}$ \\
\hline 2 & 3494.560 & 2.800 & 4 & 0.592 & $5.80 \mathrm{E}-07$ & -8.690 & -8.667 & 8.631 \\
\hline 3 & 3504.780 & $20.435^{*}$ & 4 & 0.000 & $5.70 \mathrm{E}-07$ & -8.705 & -8.674 & -8.623 \\
\hline 4 & 3508.810 & 8.054 & 4 & 0.090 & $5.70 \mathrm{E}-07^{*}$ & $-8.705^{*}$ & -8.665 & -8.600 \\
\hline \multicolumn{9}{|c|}{ Part II } \\
\hline & & \multicolumn{4}{|c|}{$\mathrm{Oil}_{t}$} & \multicolumn{3}{|c|}{ Energy $_{t}$} \\
\hline $\mathrm{Oil}_{t-1}$ & & \multicolumn{4}{|c|}{$-160^{* * *}$} & \multicolumn{3}{|c|}{$.044^{* * *}$} \\
\hline Energy $_{t-1}$ & & \multicolumn{4}{|c|}{.154} & \multicolumn{3}{|c|}{.016} \\
\hline
\end{tabular}

Panel A reports descriptive statistics on the daily returns of the WTI Crude Oil Price and CSI Energy Index for the period from January 1, 2018 to June 31, 2021, including mean, standard deviation, minimum, maximum, kurtosis and skewness. JB denotes the Jarque-Bera test for normality. The results of the JB statistic test for the two indices are all much greater than 10, proving that they do not follow a normal distribution. Panel B presents the estimation results of the VAR model. Part I shows the information criteria test results, where FPE is financial prediction error, AIC is Akaike Information Criteria, HQIC is the Hannan-Quinn Information Criteria, and SBIC is the Schwarz Information Criterion. The statistics relating to log likelihood (LL) and likelihood ratio (LR), degrees of freedom (df) and probability value (p) are also provided. Part II exhibits the estimated coefficients of the VAR model.

\section{B. Vector Autoregressive Model}

To capture the autocorrelation and correlation between the oil and energy stock markets, we adopt a VAR model, with each return series expressed by $\operatorname{VAR}(p)$, as follows:

$$
\begin{gathered}
R_{t}=c+\sum_{i=1}^{p} \phi_{i} R_{t-i}+\varepsilon_{t} \\
\varepsilon_{t} \mid \Omega_{t-1} \approx N\left(0, H_{t}\right)
\end{gathered}
$$

where $R_{t}$ is a two-dimensional random vector representing the percentage change of price, denoted as $R_{t}=\left(\text { Energy }_{t}, \text { Oil }_{t}\right)^{\prime} ; c$ is a two-vector of constants; $\phi_{i}$ is a time-invariant $2 \times 2$ matrix indicating serial correlation and spillover effects; and $\varepsilon_{t}$ is a two-vector of error terms conditional on past information $\Omega_{t-1}$ at time $t-1$.

\section{DCC-GARCH}

We use the DCC specification to obtain dynamic correlations (Engle, 2002; Tse \& Tsui, 2002). To estimate the DCC model, we first need to calculate the parameters.

The conditional variance-covariance matrix, $H_{t}$, can be written as follows:

$$
H_{t}=D_{t} R_{t} D_{t}
$$

where $D_{t}$ is the $2 \times 2$ diagonal matrix of the dynamic standard deviation and $R_{t}$ is a matrix of dynamic correlation coefficients given by

$$
R_{t}=\left[\operatorname{diag}\left(Q_{t}\right)^{-1 / 2}\right] Q_{t}\left[\operatorname{diag}\left(Q_{t}\right)^{-1 / 2}\right]
$$

The positive definite matrix with conditional heteroscedasticity, $Q_{t}$, is denoted as

$$
Q_{t}=\left(1-\theta_{1}-\theta_{2}\right) Q^{\prime}+\theta_{1}\left(v_{t-1} v_{t-1}^{\prime}\right)+\theta_{2} Q_{t-1}
$$

where $Q^{\prime}$ represents the $2 \times 2$ unconditional variance matrix of standardized residuals and $v_{t-1}$ is the standardized residual. The coefficients $\theta_{1}$ and $\theta_{2}$ of the DCC model denote the conditional correlation effects.

Second, we further explore dynamic conditional correlation, which can be expressed as

$$
\rho_{12, t}=\frac{q_{12, t}}{\sqrt{q_{11, t} q_{22, t}}}
$$

\section{Results and Discussion \\ A. VAR model estimation}

Based on the Akaike (1974) information criterion, the Bayesian information criterion (Schwarz, 1978), and Hannan-Quinn (1979) information criterion, we select a bivariate VAR model with a lag of one to examine the relation between the international crude oil market and China's energy sector. The results are shown in Panel B of Table 1.

The VAR(1) results show serial correlation in the international crude oil market. Specially, for every $1 \%$ increase in returns in China's energy sector in the last period, international oil market returns will fall by $0.16 \%$ in the current period. However, China's energy market has no influence on the international crude oil market.

We find no serial correlation for China's energy market. Moreover, the international crude oil market has a significant positive impact on the Chinese energy market, which is in line with realistic expectations. Specifically, when the oil returns in the previous period rise by $1 \%$, China's energy returns in the current period are expected to rise by $0.04 \%$. 
Table 2. The results of DCC-GARCH model.

\begin{tabular}{|c|c|c|c|}
\hline \multicolumn{4}{|c|}{ Part I GARCH $(1,1)$} \\
\hline & $\alpha$ & $\beta$ & $\alpha+\beta$ \\
\hline Oil & $0.185^{* * *}$ & $0.811^{* * *}$ & 0.996 \\
\hline Energy & $0.145^{* * *}$ & $0.657^{* * *}$ & 0.802 \\
\hline \multicolumn{4}{|c|}{ Part II DCC-GARCH $(1,1)$} \\
\hline & $\theta_{1}$ & $\theta_{2}$ & $\theta_{1}+\theta_{2}$ \\
\hline Oil-Energy & $0.076^{* *}$ & $0.729^{* * *}$ & 0.805 \\
\hline
\end{tabular}

Table 2 shows the estimated coefficients of GARCH(1,1) and DCC-GARCH(1,1).

In conclusion, the international crude oil market has a positive one-way mean spillover effect on China's energy stock market.

\section{B. DCC-GARCH model estimation}

We first use the GARCH(1,1) model to fit the volatility of international crude oil returns and China's energy returns and find that all estimated ARCH coefficients $\left(\alpha_{i}\right)$ and GARCH coefficients $\left(\beta_{i}\right)$ are positive and significant and, in particular, the value of $\alpha_{i}+\beta_{i}$ is less than one, which suggests pronounced autocorrelation in dynamic volatility. In turn, we proceed to the dynamic parameter estimation in the next step. Table 2 reports the parameters we obtain.

For the DCC results, the estimates for the first parameter, $\theta_{1}$, and the second parameter, $\theta_{2}$, are positive and significant at the $5 \%$ and $1 \%$ levels, respectively. Thus the conditional correlation between international crude oil returns and China's energy returns can be considered to be time varying. Furthermore, the sum of these estimated coefficients $\left(\theta_{1}+\theta_{2}\right)$ is less than unity, confirming the persistent volatility of the conditional correlation.

Figure 1 shows the dynamic correlation coefficient. As shown, the correlation between international crude oil returns and Chinese energy returns is volatile, with a largely positive dynamic correlation coefficient. The correlation weakens significantly in the first quarter of 2019; in contrast, it strengthens significantly in the first quarter of 2020, with a dynamic correlation coefficient of 0.7 . These changes are due to the large shocks to the international oil market during those two periods.

\section{Conclusion}

This paper empirically analyzes the spillover effects be-

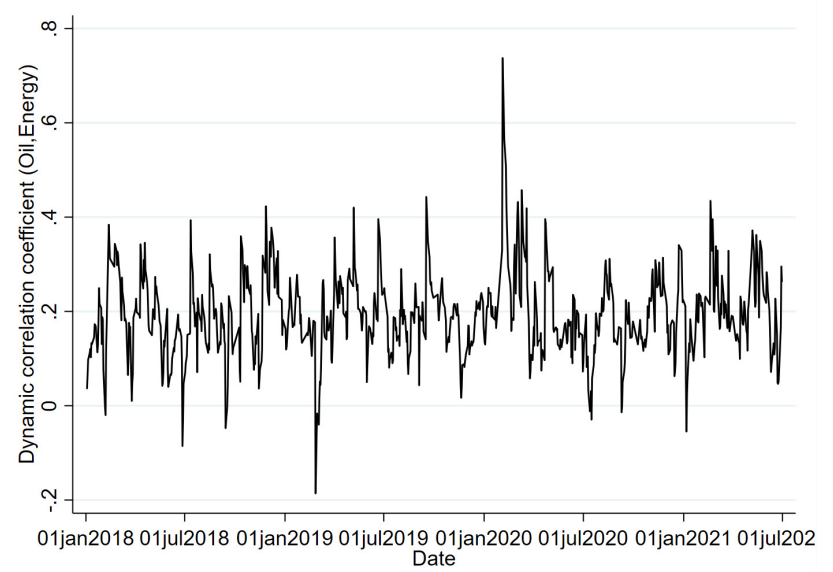

Figure 1. Dynamic correlation coefficient

Figure 1 plots the time-varying correlation coefficient between international crude oil returns and Chinese energy returns in the DCC-GARCH $(1,1)$ model.

tween international crude oil prices and Chinese energy stock prices, using a combination of a VAR model and a DCC-GARCH model. Our findings suggest that energy stock returns have a positive one-way mean spillover effect on changes in international crude oil prices. In addition, there is a significant and somewhat persistent time-varying correlation between Chinese new energy stock returns and international crude oil futures returns. To some extent, these findings indicate that the international crude oil market has a significant impact on the Chinese energy sector. Therefore, further improvements to the Chinese stock market are needed, and the government should strengthen the disclosure of information to avoid panic among retail investors during frequent oil price fluctuations. 


\section{REFERENCES}

Akaike, H. (1974). A new look at the statistical model identification [J]. IEEE Transactions on Automatic Control, 19(6), 716-723. https://doi.org/10.1109/tac.1 974.1100705

Alamgir, F., \& Amin, S. B. (2021). The nexus between oil price and stock market: Evidence from South Asia. Energy Reports, 7, 693-703. https://doi.org/10.1016/ j.egyr.2021.01.027

Awartani, B., \& Maghyereh, A. I. (2013). Dynamic spillovers between oil and stock markets in the Gulf Cooperation Council countries. Energy Economics, 36, 28-42. https://doi.org/10.1016/j.eneco.2012.11.024

Cunado, J., \& Perez de Gracia, F. (2014). Oil price shocks and stock market returns: Evidence for some European countries. Energy Economics, 42, 365-377. h ttps://doi.org/10.1016/j.eneco.2013.10.017

Diaz, E. M., Molero, J. C., \& Perez de Gracia, F. (2016). Oil price volatility and stock returns in the G7 economies. Energy Economics, 54, 417-430. https://do i.org/10.1016/i.eneco.2016.01.002

Engle, R. (2002). Dynamic conditional correlation: A simple class of multivariate generalized autoregressive conditional heteroskedasticity models. Journal of Business \& Economic Statistics, 20(3), 339-350. https://doi.org/10.1198/0735001022886184 $\underline{87}$

Escobari, D., \& Sharma, S. (2020). Explaining the nonlinear response of stock markets to oil price shocks. Energy, 213, 118778. https://doi.org/10.1016/ j.energy.2020.118778

Hannan, E. J., \& Quinn, B. G. (1979). The Determination of the Order of an Autoregression [J]. Journal of the Royal Statistical Society: Series B (Methodological), 41(2), 190-195. https://doi.org/10.1111/j.2517-6161.1 979.tb01072.x

Joo, Y. C., \& Park, S. Y. (2021). The impact of oil price volatility on stock markets: Evidences from oilimporting countries. Energy Economics, 101, 105413. h ttps://doi.org/10.1016/i.eneco.2021.105413
Li, X., \& Wei, Y. (2018). The dependence and risk spillover between crude oil market and China stock market: New evidence from a variational mode decomposition-based copula method. Energy Economics, 74, 565-581. https://doi.org/10.1016/j.ene co.2018.07.011

Maghyereh, A., \& Abdoh, H. (2021). The impact of extreme structural oil-price shocks on clean energy and oil stocks. Energy, 225, 120209. https://doi.org/1 0.1016/i.energy.2021.120209

Mokni, K. (2020). Time-varying effect of oil price shocks on the stock market returns: Evidence from oilimporting and oil-exporting countries. Energy Reports, 6, 605-619. https://doi.org/10.1016/j.egyr.20 20.03.002

Narayan, P. K., \& Sharma, S. S. (2011). New evidence on oil price and firm returns. Journal of Banking \& Finance, 35(12), 3253-3262. https://doi.org/10.1016/ j.jbankfin.2011.05.010

Phan, D. H. B., Sharma, S. S., \& Narayan, P. K. (2015). Oil price and stock returns of consumers and producers of crude oil. Journal of International Financial Markets, Institutions and Money, 34, 245-262. https://doi.org/10.1016/j.intfin.2014.11.010

Schwarz, G. (1978). Estimating the Dimension of a Model [J]. Annals of Statistics, 6(2), 461-464. https://d oi.org/10.1214/aos/1176344136

Tse, Y. K., \& Tsui, A. K. C. (2002). A multivariate generalized autoregressive conditional heteroscedasticity model with time-varying correlations. Journal of Business \& Economic Statistics, 20(3), 351-362. https://doi.org/10.1198/07350010228 8618496

Youssef, M., \& Mokni, K. (2019). Do crude oil prices drive the relationship between stock markets of oilimporting and oil-exporting countries? Economies, 7(3), 70. https://doi.org/10.3390/economies7030070 